Journal Of Metallurgical Engineering And Processing Technology,

Vol. 2, No. 2, February 2022, pp. 80-88

P-ISSN: 2723-6854, E-ISSN: 2798-1037

\title{
KAJIAN TEKNIS ALAT PEREMUK UNTUK MENINGKATKAN PRODUKSI PT. GUNUNG PUNCAK SALAM PROVINSI JAWA BARAT
}

\author{
Casimiro Orleans Martins ${ }^{1}$, Avellyn Shinthya Sari ${ }^{2}$, Ratih Hardini Kusuma Putri ${ }^{3}$, Esthi Kusdarini ${ }^{4}$, Fairus \\ Atika Redanto Putri ${ }^{5}$ \\ email: rhkputri@itats.ac.id
}

\author{
Jurusan Teknik Pertambangan - Fakultas Teknologi Mineral dan Kelautan \\ ITATS (Institut Teknologi Adhi Tama Surabaya) \\ Jl. Arif Rahman Hakim No.100 60117 Surabaya, Jawa \\ Timur, Indonesia
}

\section{RINGKASAN}

PT. Gunung Puncak Salam merupakan perusahaan yang bergerak dalam kegiatan pertambangan batu andesit dan sebagai pemasok di wilayah Jawa Barat dan sekitarnya. PT. Gunung Puncak Salam memiliki usaha pertambangan (IUP) seluas 24 Ha tetapi yang di ijinkan untuk ditambang dari Dinas Pertambangan setempat adalah seluas 6 Ha di kampung cikuya, Desa Lagadar, Kecamatan Margaasih, Kabupaten Bandung, Provinsi Jawa Barat. Keberadaan perusahaan tersebut diharapkan dapat berdampak positif terhadap peningkatan perekonomian diwilayah sekitar perusahaan khususnya di Kabupaten Bandung.

Pengolahan batu andesit yang dilakukan PT. Gunung Puncak Salam terdiri dari tiga unit permuk batuan yaitu permuk pertama (Primary Jaw Crusher), permuk kedua (Secondary Jaw Crusher), dan permuk ke tiga (Tertiary Vertical Shaft Crusher). Tetapi dalam prakteknya banyak kendala yang di hadapi. Objek penelitian hanya terbatas pada Unit Crushing Plant dengan sasaran produksi yang direncanakan sebesar 800 ton/hari atau 100 ton/jam, sedangkan pada kenyatannya target belum tercapai.

Penelitian ini menganalisis produksi pada pengolahan (unit crushing plant) dengan kesesuaian target produksi serta kapasitas dan efisiensi dari unit peremuk. Peralatan pabrik peremuk yang dipilih antara lain Vibrating grizzly feeder merk AEG Type A180MYR1 kapasitas 150 ton/jam, Single deck vibrating screen merk

Metso Premier Inclined Screen CVB201TM, Primary Jaw crusher merk VEMA Type S280-8 (600-900mm) kapasitas 150 ton/jam, Secondary Jaw crusher merk SHANBAO Type E250 x 1200 PEX kapasitas 120 ton/jam, Tertiary Vertical Shaft crusher merk Vertical Crusher Type E250 x 1200 PEX kapasitas 100 ton/jam, Belt conveyor (BC.1-BC8) kapasitas 80 ton/jam, Screen (I) merk YUEME Type YP-725C kapasitas 226 ton/jam, volume Hopper sebesar 20,33 $\mathrm{m}^{3}$ sehingga kapasitas 28,46 ton/jam. Produk Unit Crushing Plant pada saat ini sebesar 618 ton/hari atau 70 ton/jam denga waktu kerja efektif sebesar 6,95 jam/hari. 


\section{PENDAHULUAN}

Unit pengolahan memegang peranan penting dalam kelangsungan Usaha Pertambangan, Karena Unit pengolahan merupakan salah satu penentu dari kualitas produk yang dihasilkan.Seiring dengan pesatnya pertumbuhan ekonomi dan perkembangan pada sektor konstruksi, maka kebutuhan akan material atau batu andesit cukup tinggi, terutama untuk melakukan pembangunan fisik seperti pembangunan gedung, aspal, jalan kereta api, bendungan dan lain sebagainya.

Untuk mencukupi kebutuhan bahan galian tersebut, maka PT. Gunung Puncak Salam sebagai salah satu produsen batu andesit berusaha untuk mencukupi kebutuhan diwilayah Jawa Barat. Kelancaran dalam proses permuka batu andesit merupakan salah satu faktor yang mendukung ketersedian batu belah dan batu pecah untuk memenuhi kebutuhan konsumen. Berkaitan dengan hal itu,maka penulis melakukan kajian teknis alat permuk untuk meningkatkan produksi permukan batuan andesit di PT. Gunung Puncak Salam.

PT. Gunung Puncak Salam merupakan perusahaan yang bergerak dalam kegiatan pertambangan batu andesit dan sebagai pemasok di wilayah Jawa Barat dan sekitarnya. PT. Gunung Puncak Salam memiliki usaha pertambangan (IUP) seluas $24 \mathrm{Ha}$ tetapi yang di ijinkan untuk ditambang dari Dinas Pertambangan setempat adalah seluas 6 Ha di kampung cikuya, Desa Lagadar, Kecamatan Margaasih, Kabupaten Bandung, Provinsi Jawa Barat. Keberadaan perusahaan tersebut diharapkan dapat berdampak positif terhadap peningkatan perekonimian diwilayah sekitar perusahaan khususnya di Kabupaten Bandung.

Pengolahan batu andesit yang dilakukan PT. Gunung Puncak Salam terdiri dari tiga unit permuk batuan yaitu permuk pertama (Primary Jaw Crusher), permuk kedua (Secondary Jaw Crusher), dan permuk ke tiga (Tertiary Vertical Shaft Crusher). Tetapi dalam prakteknya banyak kendala yang di hadapi. Objek penelitian hanya terbatas pada Unit Crushing Plant dengan sasaran produksi yang direncanakan sebesar 800 ton/hari atau 100 ton/jam, sedangkan pada kenyatannya target belum tercapai.

\section{Metode Penelitian}

Penelitian ini dimulai dengan studi literatur dan dilanjutkan dengan pengambilan data secara langsung (data primer) maupun tidak langsung (data sekunder) yang dilanjutkan dengan suatu pengolahan dan analisis data sehingga didapatkan suatu kesimpulan dan saran yang merupakan hasil akhir dari suatu penelitian. Berikut diagram alir penelitian

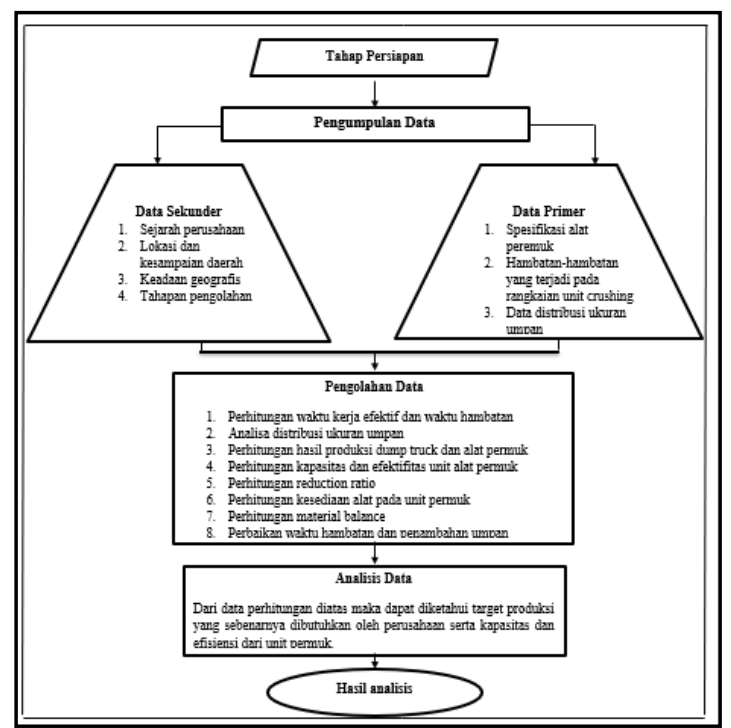

Gambar 1.Diagram Alir Penelitian

\section{HASIL PENELITIAN \\ 3.1 Hasil Pengamatan Rangkaian Crushing \\ Plant}

Berdasarkan hasil pengamatan di PT. Gunung Puncak Salam di Unit Crushing Plant, proses peremukan material batu andesit dilakukan dengan beberapa tahap untuk mencapai sasaran produksi 800 ton/hari. Proses peremukan atau pengecilan ukuran dibagi menjadi tiga tahapan yaitu tahapan Primary Jaw Crusher, Secondary Jaw Crusher dan Tertiary Vertical Shaft Crusher. Material atau batu andesit yang di angkut dump truck dari lokasi penambangan langsung menuju ke tempat pengolahan, kemudian ditumpahkan ke Hopper. Batu andesit yang ditumpahkan ke Hopper langsung masuk ke Vibrating Feeder, ini mengumpan batu andesit yang berukuran $+5 \mathrm{~cm}$ sebesar $72 \%$ masuk ke Primary Jaw Crusher untuk di hancurkan menjadi material yang lebih kecil ukurannya, sedangkan material yang berukuran lebih kecil dari $5 \mathrm{~cm}$ sebesar $28 \%$ akan diloloskan ke belt conveyor (BC-1). Pada proses selanjutnya material hasil dari Primary Jaw Crusher dan material yang lolos dari Vibrating Feeder akan tertampung pada Belt Conveyor (BC-1), kemudian dilarikan menuju Hopper kecil (penampung ke -2). Setelah dari Hopper 2, akan dilarikan dengan Belt Conveyor (BC-2) yang membawa menuju Secondary Jaw Crusher setelah diproses, material akan dilarikan ke Belt Conveyor (BC-3), kemudian menuju ke ayakan (Screen).

Setelah diproses material yang lolos akan dilarikan pada Belt Conveyor yang telah dibagi menjadi 4 Belt Conveyor under size yaitu (BC-4) yang memproduksi produk $20 \mathrm{~mm}-30 \mathrm{~mm}$, (BC-5) yang memproduksi produk $10 \mathrm{~mm}-20 \mathrm{~mm}$, dan (BC-7) yang memproduksi produk $5 \mathrm{~mm}-10 \mathrm{~mm}$, dan (BC-8) yang memproduksi produk $0 \mathrm{~mm}-5 \mathrm{~mm}$, dan untuk Belt Conveyor Over Size (BC-6) akan dikembalikan ke Tertiary Vertical Shaft Crusher untuk di produksi kembali dan setelah diproses akan dilarikan kembali melalui Belt Conveyor (BC-3) menuju ayakan (Screen). 3.1.1 Proses Peremukan Batuan Andesit 


\section{Journal Of Metallurgical Engineering And Processing Technology,}

Vol. 2, No. 2, February 2022, pp. 80-88

P-ISSN: 2723-6854, E-ISSN: 2798-1037

Proses pengolahan di PT. Gunung Puncak Salam yaitu melalui 4 tahapan yang pertama adalah Primary Crusher menggunakan Jaw Crusher, yang kedua adalah Secondary Crusher menggunakan Jaw Crusher ukuran kecil, yang ke tiga Tertiary Crusher menggunakan Vertical Shaft Crusher lalu dilanjutkan dengan tahapan ke empat yaitu sizing menggunakan Screen fourfold (4) deck berikut ini adalah alat dari rangkaian peremukan yaitu :
1 unit Hopper
1 unit Vibrating Feeder
1 unit Jaw Crusher
1 unit Jaw Crusher ukuran kecil
1 unit Vertical Shaft Crusher
1 unit Screen fourfold (4) deck
8 unit Belt Conveyor

\subsubsection{Proses Peremukan Primer}

Kegiatan pengecilan ukuran dilakukan dengan cara memecah atau menghancurkan bongkahbongkahan batu besar menjadi pecah-pecahan batu yang lebih kecil sebagai langkah awal yang biasa dilakukan dalam proses pengecilan ukuran batu adalah :

Batuan hasil peledakan yang berasal dari lokasi penambangan memiliki ukuran $700 \mathrm{~mm}$ diangkut menggunakan Dump Truck tersebut langsung dimasukan ke dalam Hopper.

Selanjutnya melalui Vibrating Feeder yang berukuran $600 \mathrm{~mm}$, apabila ada umpan yang berukuran kurang dari $5 \mathrm{~cm}$ maka akan langsung jatuh ke Belt Conveyor 1 (BC-1),sedangkan yang ukuran lebih dari $5 \mathrm{~cm}$ akan menuju atau di umpankan ke mulut Primary Jaw Crusher kemudian jatuh ke Belt Conveyor 1 (BC-1) lalu menuju ke proses selanjutnya yaitu Secondary Jaw Crusher.

3.1.3 Proses Peremukan Sekunder

Proses peremukan sekunder yang dilakukan di PT.Gunung Puncak Salam diawali dari material hasil dari Primary Crushing akan dibawah oleh Belt Conveyor 1 (BC-1) menuju ke Hopper kecil atau Hopper 2, dan selanjutnya akan dilarikan dengan Belt Conveyor (BC-2) yang membawa menuju Secondary Jaw Crusher sebagai awal dari proses sekunder.

\subsubsection{Proses Peremukan Tertiary}

Proses peremukan tertiary yang dilakukan di PT.Gunung Puncak Salam diawali dari material hasil dari ayakan yang masih berukuran besar atau over size akan dilarikan dengan Belt Conveyor 6 (BC-6) menuju Tertiary Crusher lalu dimasukan ke dalam Vertical Shaft Crusher sebagai awal dari tertiary.

3.1.5 Pengamatan Produksi Unit Peremuk

Tujuan peremukan (crushing) adalah salah satu proses pengolahan dari bagian hasil penambangan yang berupa batu andesit yang di olah menjadi batu produk untuk di pasarkan. Dari rangkaian permukan di PT.Gunung Puncak Salam menggunakan Hopper, Feeder, Jaw Crusher, Jaw Crusher ukuran kecil, Vertical Shaft Crusher, dan Belt Conveyor. Rangkaian peremukan dapat dilihat pada (Gambar. 2)

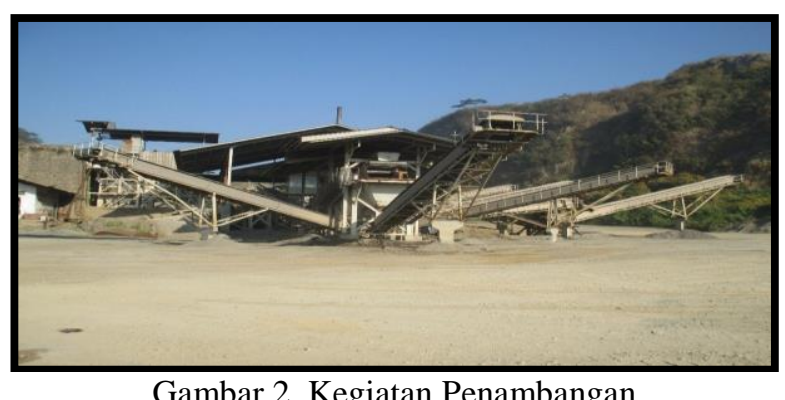

\subsubsection{Hopper}

Hopper adalah alat pelengkap pada rangkaian unit peremuk yang berfungsi sebagai tempat penerima material umpan atau tempat penampung sementara sebelum material tersebut masuk ke dalam alat permuk. Hopper ini terbuat dari beton yang dilapisi oleh lebarnya baja pada dindingdindingnya dengan tujuan agar terhindar dari akibat gesekan dan benturan dinding. Hasil perhitungan menunjukan bahwa volume Hopper sebesar 20,333 m3, sehingga kapasitas desain hopper sebesar 28,46

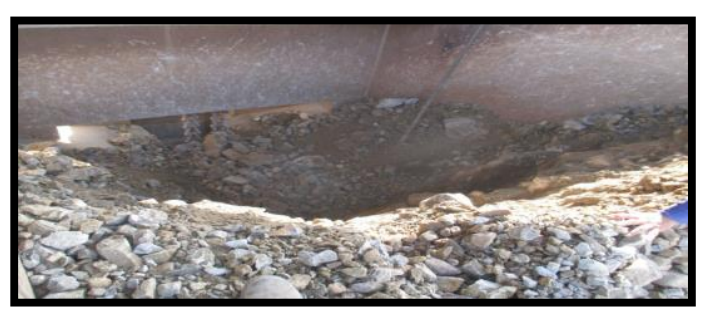

ton/jam.

\section{Gambar 3 Hopper PT. GPS}

\subsubsection{Vibrating Feeder}

Vibrating Feeder berfungsi sebagai alat pengumpan pada rangkaian unit permuk. Kapasitas desain dari Vibrating Feeder sebesar 150 ton/jam dengan ukuran umpan maksimum sebesar $60 \mathrm{~cm}$

\subsubsection{Peralatan Peremukan}

Berdasarkan pengamatan di lapangan alat peremukan yang digunakan di PT. Gunung Puncak Salam adalah Primary Jaw Crusher dengan kapasitas desain 150 ton/jam (Lampiran D).Sedangkan kapasitas desain Secondary Jaw Crusher sebesar 120 ton/jam (Lampiran E), dan kapasitas desain Tertiary Vertical Shaft Crusher sebesar 100 ton/jam (Lampiran F). Unit permuk meliputi Primary Jaw Crusher, Secundary Jaw Crusher dan Tertiary Vertical Shaft Crusher di PT. Gunung Puncak Salam dapat dilihat pada (gambar 4.3) 


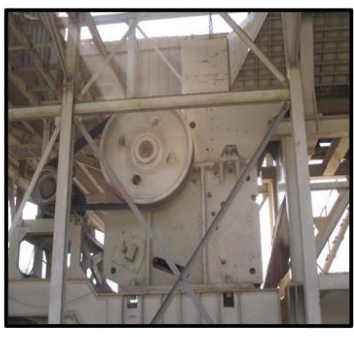

Sumber: Dokumentasi Penulis 2019 Gambar 3.3 (a)

Primary Jaw Crusher

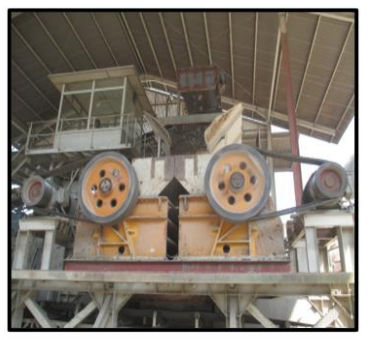

Sumber: Dokumentasi Penulis 2019 Gambar 3.3 (b) Secondary Jaw Crusher

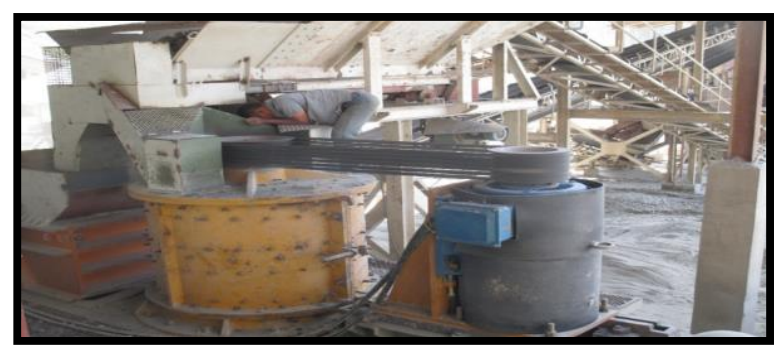

Gambar 3.3 (c)

Tertiary Vertical Shaft Crusher

\subsection{Produksi Nyata Unit Crushing Plant}

\subsubsection{Kapasitas Nyata Unit Peremuk}

Penilaian terhadap hasil kerja peralatan

Unit Crushing Plant batu andesit di PT. Gunung

Puncak Salam yaitu untuk mengetahui

kemampuan dari peralatan pada saat ini. Dengan demikian perlu diketahui sampai sejauh mana tingkat produksi hasil kerja peralatan Unit

Crushing Plant agar tercapainya target produksi.

\subsubsection{Produksi Nyata Vibrating Feeder}

Berdasarkan perhitungan ritase dump truck hasil pengangkutan material batu andesit adalah 70 ton/jam atau 618,1 ton/hari. Material yang berukuran lebih besar dari $5 \mathrm{~cm}$ sebesar $72 \%$ $(50,40$ ton/jam $)$ sedangkan material yang berukuran kurang dari $5 \mathrm{~cm}$ sebesar $28 \%(19,60$ ton/jam)

\subsubsection{Produksi Nyata Primary Jaw Crusher}

Berdasarkan hasil pengamatan kapasitas nyata Primary Jaw Crusher dihitung berdasarkan dari jumlah material yang masuk ke jaw crusher dengan ukuran lebih dari $5 \mathrm{~cm}$. Dari hasil distribusi ukuran material menunjukkan bahwa material yang lebih dari $5 \mathrm{~cm}$ yaitu sebanyak $72 \%$, sehingga dari hasil tersebut dapat dihitung kapasitas nyata Jaw Crusher adalah 50,40 ton/jam.

\subsubsection{Produksi Nyata Belt Conveyor}

Pengamatan atau perhitungan kapasitas nyata Belt Conveyor hanya dilakukan pada Belt Conveyor (BC-4), Belt Conveyor (BC-5), Belt Conveyor (BC-7), dan Belt Conveyor (BC-8), dengan cara melakukan pengambilan contoh produk pada Belt Conveyor. Hasil perhitungan kapasitas nyata Belt Conveyor adalah sebagai berikut :
- Kapasitas nyata belt conveyor 4 (BC-4) sebesar 20,22 ton/jam

- Kapasitas nyata belt conveyor 5 (BC-5) sebesar 15,12 ton/jam

- Kapasitas nyata belt conveyor 7 (BC-7) sebesar 17,30 ton/jam

- Kapasitas nyata belt conveyor 8 (BC-8) sebesar 15,20 ton/jam

\subsubsection{Produksi Nyata Screen}

Dari hasil perhitungan kapasitas nyata Ayakan (Screen) adalah sebesar 70 ton/jam, sedangkan efektifitas kerja alatnya yaitu $30 \%$.

3.2.6 Efektifitas Penggunaan Peralatan Unit Permuk

Efektivitas penggunaan ini adalah perbandingan antara kapasitas nyata yang dicapai pada saat ini dengan kapasitas desainnya. Berdasarkan pengamatan hasil perhitungan maka dapat dilihat efektifitas penggunaan peralatan di Unit Crushing Plant, seperti pada tabel sebagai berikut :

Tabel 1. Efektifitas penggunaan peralatan unit peremukan

\begin{tabular}{|c|l|c|c|c}
\hline No & \multicolumn{1}{|c|}{ Nama alat } & $\begin{array}{c}\text { Kapasitas } \\
\text { desain } \\
\text { (ton/jam) }\end{array}$ & $\begin{array}{c}\text { Kapasitas } \\
\text { nyata } \\
\text { (ton/jam) }\end{array}$ & $\begin{array}{c}\text { Efektifitas } \\
\mathbf{( \% )}\end{array}$ \\
\hline 1 & Vibrating feeder & 150 & 70 & $46,66 \%$ \\
\hline 2 & Jaw Crusher & 150 & 50,40 & $33,61 \%$ \\
\hline 3 & BC.4 & 80 & 20,22 & $25,27 \%$ \\
\hline 4 & BC.5 & 80 & 15,12 & $18,10 \%$ \\
\hline 5 & BC.7 & 80 & 17,30 & $21,62 \%$ \\
\hline 6 & BC.8 & 80 & 15,20 & $19,00 \%$ \\
\hline 7 & Screen (4 dec) & 226 & 70 & $30 \%$ \\
\hline
\end{tabular}

\subsection{Hambatan - hambatan yang terjadi pada} Rangkaian Unit Crushing Plant

3.3.1 Waktu Produksi Efektif dan Efisiensi Waktu Kerja

Untuk mengetahui waktu produksi efektif terlebih dahulu dilakukan pengamatan - pengamatan terhadap hambatan yang terjadi selama kegiatan produksi berlangsung. Semua hambatan yang terjadi selama operasi dibedakan menjadi hambatan yang disebabkan oleh faktor manusia dan hambatan yang disebabkan oleh faktor alat, dapat dilihat pada tabel sebagai berikut :

Tabel 2. Hambatan-hambatan yang disebabkan oleh faktor manusia

\begin{tabular}{|c|l|c|}
\hline No & \multicolumn{1}{|c|}{ Jenis hambatan } & Jumlah (menit) \\
\hline 1 & Persiapan memulai bekerja & 60 \\
\hline 2 & Berhenti bekerja sebelum waktunya istrahat & 6,34 \\
\hline 3 & Persiapan memulai bekerja setelah jam istrahat & 10 \\
\hline 4 & Berhenti bekerja sebelum waktunya pulang & 3,46 \\
\hline \multicolumn{2}{|c|}{ Total } & $\mathbf{7 9 , 8 0}$ \\
\hline
\end{tabular}




\section{Journal Of Metallurgical Engineering And Processing Technology,}

Vol. 2, No. 2, February 2022, pp. 80-88

P-ISSN: 2723-6854, E-ISSN: 2798-1037

Sedangkan hambatan yang disebabkan oleh faktor alat, biasanya terjadi karena kerusakan pada unit peremuk, sehingga mengakibatkan berhentinya operasi yaitu sebagai berikut :

Gangguan pada Vibrating Feeder

Gangguan yang terjadi pada Vibrating Feeder berupa terjadinya material batu andesit yang terjebak ditengah batang-batang baja yang membentuk ukuran lubang bukaan tertentu.

Gangguan pada Primary Jaw Crusher

Gangguan ini berupa double shaft hammer crusher berhenti akibat terlalu besar ukuran batuan yang melebihi kapasitas, yang menyebabkan terganggunya proses peremukan. Crusher

Gangguan pada Tertiary Vertical Shaft

Gangguan ini berupa material batu andesit terjebak pada dua lubang saluran menuju crusher yang menyebabkan terganggunya proses permukaan.

Gangguan pada Hopper

Gangguan ini berupa menunggu proses peremukan pada secondary Crusher, dimana kapasitas Crushernya lebih kecil dari kapasitas Hopper yang memberi material umpan.

Tabel 3. Hambatan-hambatan yang terjadi karena faktor alat

\begin{tabular}{|c|l|c}
\hline No & \multicolumn{1}{|c|}{ Jenis Hambatan } & Waktu (menit) \\
\hline 1 & Gangguan pada Vibrating Feeder & 0,96 \\
\hline 2 & Gangguan pada Jaw Crusher & 22,84 \\
\hline 3 & Gangguan pada Secondary Jaw Crusher & 0 \\
\hline 4 & Gangguan pada Tertiary Vertical Shaft Crusher & 4,76 \\
\hline 5 & Gangguan pada Hopper & 4,46 \\
\hline 6 & Gangguan pada Belt Conveyor & 0 \\
\hline 7 & Gangguan pada Screen & 0 \\
\hline & Total & $\mathbf{3 3 , 0 3}$ \\
\hline & & \\
\hline & &
\end{tabular}

Jadi untuk mengetahui waktu hambatan yang disebabkan oleh faktor manusia dan faktor alat, maka pengamatan waktu hambatan perhari untuk mengetahui persentase waktu produksi efektif adalah sebagai berikut :

$\mathrm{We}=\mathrm{Wt}-(\mathrm{Wn}+\mathrm{Wu})$

Dimana : menit )

$\mathrm{Wt}=$ Waktu kerja yang tersedia ( 530

$\mathrm{Wu}=$ Waktu hambatan yang disebabkan oleh faktor manusia (33,03 menit)

$\mathrm{Wn}=$ Waktu hambatan yang disebabkan oleh faktor alat ( 79,80 menit )

Maka :

$$
\begin{aligned}
\mathrm{We} & =530-(33,03+79,80) \\
& =530-112,83 \\
& =412,17 \text { menit/hari atau } 6,95 \mathrm{jam} / \mathrm{hri}
\end{aligned}
$$

Jadi rata-rata waktu produksi efektif setiap hari yang diperoleh adalah 412,17 menit/hari atau $6,95 \mathrm{jam} / \mathrm{hari}$. Waktu produksi efektif yang digunakan untuk perhitungan efisiensi kerja dengan persamaan :

$$
\mathrm{E}=\mathrm{We} / \mathrm{Wt} \times 100 \%
$$

Dimana :

$\mathrm{We}=$ Waktu produksi efektif per hari ( 412,17 menit )

Wt $=$ Waktu kerja yang tersedia per hari ( 530 menit )

Maka :

$\mathrm{E}=\mathrm{We} / \mathrm{Wt} \times 100 \%$

$=412,17 / 530 \times 100 \%$

$=77,76 \%$

Jadi hasil perhitungan nilai efisiensi waktu kerja rata-rata per hari sebesar $77,76 \%$.

3.3.2 Nisbah Reduksi ( Reduction Ratio )

Nilai reduction ratio ditentukan oleh kemampuan dari alat peremukannya sehingga besar kecilnya nilai reduction ratio dapat digunakan sebagai ukuran keberhasilan suatu proses peremukan. Dalam penilaian ini dilakukan pengukuran diperoleh diameter maksimum rata-rata material umpan adalah $62 \mathrm{~cm}$ dan diameter maksimum rata-rata produk adalah $8,55 \mathrm{~cm}$. Dari pengukuran yang diperoleh tersebut maka dapat dihitung besarnya nilai reduction ratio yaitu sebesar 7,25 .

3.3.3 Neraca Bahan ( Material Balance )

Neraca bahan merupakan neraca suatu keseimbangan pada pengolahan bahan galian dimana jumlah partikel umpan yang masuk dalam unit pengolahan jumlahnya akan sama dengan jumlah material yang keluar, jadi untuk mengetahui jumlah kehilangan material pada unit peremukan adalah sebagai berikut :

$\mathrm{L}=\mathrm{F}-\mathrm{P}$

$=70$ ton $/ \mathrm{jam}-67,84$ ton $/ \mathrm{jam}$

$=2,16$ ton $/ \mathrm{jam}$

Keterangan :

$\mathrm{F}=$ jumlah material umpan (ton/jam)

$\mathrm{P}=$ jumlah produk (ton/jam)

$\mathrm{L}=$ jumlah kehilangan material (ton/jam)

3.3.4 Perbaikan Hambatan - Hambatan yang terjadi di unit crushing plant

3.3.4.1 Perbaikan waktu hambatan

Perbaikan waktu hambatan dilakukan dengan cara mengurangi waktu hambatan yang terjadi baik karena faktor manusia dan faktor alat dan mengoptimalkan waktu kerja efektif. Dari hasil perhitungan dan pengamatan waktu kerja yang tersedia 530 menit atau 8,83 jam/hari,waktu hambatan karena faktor alat sebesar 33,03 dan rata rata waktu hambatan karena faktor manusia sebesar 79,80 menit. Waktu produksi efektif perhari 412,17 menit atau 6,95 jam/hari dan memperoleh efektifitas waktu kerja sebesar $77,76 \%$. Setelah melakukan perbaikan waktu hambatan diperoleh waktu kerja efektif produksi sebesar 505 menit atau 8,41 jam/hari, waktu hambatan faktor alat tidak ada dan waktu hambatan rata-rata faktor manusia sebesar 25 menit dan memperoleh efektifitas kerja setelah perbaikan $95,28 \%$. Maka produksinya menjadi 588,7 ton/hari.

\subsubsection{Perbaikan Umpan Masuk}

Perbaikan umpan masuk dilakukan dengan menambahkan ritase dump truck untuk 


\section{Journal Of Metallurgical Engineering And Processing Technology,}

Vol. 2, No. 2, February 2022, pp. 80-88

P-ISSN: 2723-6854, E-ISSN: 2798-1037

meningkatkan produksi. Pada pengamatan dan perhitungan didapatkan ritase dump truck sebelum melakukan perbaikan sebanyak $7 \mathrm{kali} / \mathrm{jam}$ dengan kapasitas dump truck 10 ton, dan waktu efektif produksi sebelum perbaikan sebesar 412,17 menit/hari atau $6,95 \mathrm{jam} / \mathrm{hari}$ dan produksi sebelum perbaikan hanya sebesar 70 ton/jam atau 618,1 ton/hari. Setelah melakukan perbaikan umpan masuk diperoleh ritase dump truck sebanyak 9 kali, dengan hasil produksi setelah perbaikan sebesar 625,5 ton/hari.

3.3.4.3 Perbaikan menggunakan penggabungan antara perbaikan waktu hambatan dan perbaikan umpan masuk

Hasil pengamatan dilapangan menunjukan waktu kerja yang tersedia adalah sebesar 530 menit/hari atau 8,83 jam/hari, dengan adanya waktu hambatan rata-rata disebabkan oleh faktor manusia sebesar 79.80 menit dan hambatan karena faktor alat sebesar 33,03 menit maka waktu kerja efektif pada unit Crushing adalah 412,17 menit/hari atau 6,95 jam/hari. Sehingga untuk mendapatkan waktu produksi yang maksimal maka perlu dilakukan perbaikan terhadap hambatan hambatan tersebut. Berdasarkan hasil pengamatan dan perhitungan maka rata - rata produksi nyata pada unit Crushing Plant adalah sebesar 618,1 ton/hari atau 70 ton/jam. Sehingga perlu dilakukan perbaikan waktu hambatan untuk meningkatkan produksi. Berdasarkan perbaikan terhadap waktu hambatan yang terjadi maka kerja efektif pada produksi Unit Crushing dapat ditingkatkan dari $6,95 \mathrm{jam} / \mathrm{hari}$ manjadi $8,41 \mathrm{jam} / \mathrm{hari}$, sehingga dengan adanya waktu kerja efektif 8,41 jam/hari,maka akan meningkatkan hasil produksi sebesar 841 ton/hari.

\subsection{Analisa Produksi Nyata Unit Crushing Plant}

Unit Crushing Plant pada PT. Gunung Puncak Salam merencanakan sasaran produksi sebesar 800 ton/hari tetapi berdasarkan hasil pengamatan dan perhitungan terhadap kemampuan alat yang ada pada Unit Crushing Plant baru mencapai sasaran produksi sebesar 618,1 ton/hari atau 70 ton/jam.

Sehubungan dengan sasaran produksi tersebut diatas dan waktu operasi yang telah ditetapkan 530 menit/hari atau 8,83 jam/hari, maka akan diadakan kajian teknis untuk pencapaian sasaran produksi terhadap sistem Unit Crushing Plant batu andesit di PT. Gunung Puncak Salam, tujuan dari penelitian ini adalah untuk mengetahui sampai sejauh mana kemampuan alat atau kapasitas Unit Crushing Plant pada saat ini dan kemungkinan untuk dapat ditingkatkan, supaya mencapai sasaran produksi berdasarkan ritase yang diinginkan oleh perusahaan.

\subsection{Faktor-faktor yang Berpengaruh Terhadap}

\section{Proses Produksi}

\subsubsection{Analisa Terhadap Pengumpanan}

Pengumpanan menjadi salah satu parameter baik atau buruknya kinerja dari Crushing Plant karena dengan ukuran pengumpanan yang besar akan sangat berpengaruh pada proses permukan.Pada saat ini yang mempengaruhi proses produksi salah satunya adalah ukuran material yang besar atau berukuran besar maka akan terjadi umpan macet dan akan mengurangi jumlah produksi.

Hal ini menunjukan bahwa semakin banyak batu yang berukuran besar maka waktu permukan semakin lama dan jika itu terjadi maka akan mengakibatkan waktu hambatan, namun waktu hambatan ini bisa dihindari dengan melakukan pencegahan dan mengurangi waktu hambatan.

3.5.2 Analisa Terhadap Proses Unit Peremukan

Proses pengumpanan harus diperhatikan untuk kelancaran kegiatan peremukan oleh Unit Crushing Plant pada saat peremukan batu Andesit berlangsung.

\subsubsection{Produksi Vibrating Feeder}

Berdasarkan perhitungan input ritase dump truck produksi batu Andesit PT. Gunung Puncak Salam sebesar 618,1 ton/hari untuk Unit Crushing Plant, sehingga untuk setiap jamnya sebesar 70 ton/jam (Lampiran $\mathrm{K}$ ), dengan target produksi tersebut maka diperlukan pengumpanan material batu Andesit oleh Dump Truck sebanyak 61 kali/hari atau $7 \mathrm{kali} / \mathrm{jam}$

Dilihat dari kapasitas desain Vibrating Feeder dan produksi nyata Vibrating Feeder maka dapat dilakukan penambahan pengumpanan guna memenuhi target produksi dan mengoptimalkan penggunaan dari Vibrating Feeder, maka besarnya penambahan pengumpanan oleh Dump Truck adalah sebanyak $71 \mathrm{kali} / \mathrm{hari}$ atau $8 \mathrm{kali} / \mathrm{jam}$.

Efektifitas Vibrating Feeder pada produksi nyata yang menghasilkan sebesar 46,66 \%, dengan adanya penambahan pengumpanan material batu andesit maka efektifitas Vibrating Feeder meningkat menjadi $100 \%$.

3.5.4 Produksi Jaw Crusher

Hasil perhitungan kapasitas nyata alat permuk Primary Jaw Crusher pada unit crushing berdasarkan umpan oleh dump truck adalah 50,40 ton/jam dengan kapasitas desain primary jaw crusher sebesar 150ton/jam, maka produksi belom terpenuhi sehingga perlu dilakukan penambahan umpan.

3.5.5 Produksi Hopper

Hopper berfungsi sebagai tempat penampungan umpan sementara. Gangguan ini berupa menunggu proses peremukan pada Secondary Crusher, dimana kapasitas Crushernya lebih kecil dari kapasitas Hopper yang memberi material umpan, Hambatan - hambatan yang terjadi di Hopper dari hasil pengamatan rata-rata sebesar 4,46 menit/hari dan kapasitas desainnya sebesar 170 ton/jam.

\subsubsection{Produksi Belt Conveyor}

PT. Gunung Puncak Salam menggunakan 8 Unit Belt Conveyor di Crushing Plant dimana setiap Belt Conveyor mempunyai kapasitas desain yang 


\section{Journal Of Metallurgical Engineering And Processing Technology,}

Vol. 2, No. 2, February 2022, pp. 80-88

P-ISSN: 2723-6854, E-ISSN: 2798-1037

sama. Tetapi untuk mengetahui produk yang dialirkan melalui belt conveyor dari screen menggunakan 4 unit belt conveyor dengan masingmasing Belt Conveyor dari BC-4, BC-5, BC-7 dan $\mathrm{BC}-8$ yang mempunyai kapasitas desain antara lain

- Belt conveyor $4(\mathrm{BC}-4)=80$ ton/jam

- Belt conveyor $5(\mathrm{BC}-5)=80$ ton/jam

- Belt conveyor $7(\mathrm{BC}-7)=80$ ton/jam

- Belt conveyor $8(\mathrm{BC}-8)=80$ ton/jam Dari hasil pengamatan dan perhitungan berdasarkan kapasitas teoritis yaitu :

- Kapasitas teoritis belt conveyor 4 ( BC-4 ) sebesar 296,10 ton/jam

- Kapasitas teoritis belt conveyor 5 ( BC-5 ) sebesar 296,10 ton/jam

- Kapasitas teoritis belt conveyor 7 ( BC-7 ) sebesar 296,10 ton/jam

- Kapasitas teoritis belt conveyor 8 ( BC-8) sebesar 296,10 ton/jam

Dari hasil pengamatan dan perhitungan berdasarkan kapasitas nyata yaitu :

- Kapasitas nyata belt conveyor 4 (BC-4) sebesar 20,22 ton/jam

- Kapasitas nyata belt conveyor 5 (BC-5) sebesar 15,12 ton/jam

- Kapasitas nyata belt conveyor 7 (BC-7) sebesar 17,30 ton/jam

- Kapasitas nyata belt conveyor 8 (BC-8) sebesar 15,20 ton/jam

Untuk mengetahui efektifitas dari masingmasing Belt Conveyor produk dengan cara menghitung kapasitas desain dan kapasitas nyata maka dapat diketahui nilainya sebesar :

- Belt conveyor 4 (BC-4) sebesar 25,27\%

- Belt conveyor 5 (BC-5) sebesar 18,10\%

- Belt conveyor 7 (BC-7) sebesar 21,62\%

- Belt conveyor 8 (BC-8) sebesar 19,00\%

\subsubsection{Produksi Screen}

Berdasarkan pengamatan dan perhitungan pada Unit Crushing Plant di PT. Gunung Puncak Salam menggunakan Screen Merek Yueme Type YP-725C dengan kapasitas desainnya sebesar 226 ton/jam (Lampiran H).Efektifitas Screen yang ada di Unit Crushing Plant menghasilkan nilai sebesar $30 \%$ dengan adanya penambahan pengumpanan material batu andesit maka efektifitas Screen meningkat menjadi $66,37 \%$

\subsubsection{Penilaian Reduction Ratio}

Reduction ratio merupakan penentuan keberhasilan suatu peremukan pada unit crushing plant, dari hasil pengamatan yang dilakukan dilapangan menunjukan bahwa ukuran umpan terbesar adalah $62 \mathrm{~cm}$ dan ukuran umpan produk terbesar adalah $8,55 \mathrm{~cm}$ sehingga memiliki Reduction Ratio sebesar 7,25 cm.

3.5.10 Vibrating Feeder

a.Kesediaan Mekanis (Mechanical Availability)

Kesediaan mekanis (Mechanical Availibility) pada Vibrating Feeder adalah sebesar 99,86\% yang berarti bahwa waktu yang diperlukan untuk memperbaikan karena kerusakan pada alat sebesar $0,14 \%$ dari waktu kerja alat.

b. Kesediaan Fisik (Physical Availability)

Kesediaan fisik (Physical Avaibility) pada Vibrating Feeder adalah sebesar 99,87\% yang berarti bahwa waktu yang hilang karena berbagai alasan, baik karena kerusakan alat atau hambatan lainnya yaitu sebesar $0,13 \%$ dari waktu kerja yang dijadwalkan.

c. Kesediaan pemakaian (Use Of Avaibility)

Kesediaan pemakaian (Use Of Avaibility) pada Vibrating Feeder adalah sebesar 88,89\% sehingga tingkat penggunaan alat pada saat alat tersebut dapat bekerja cukup tinggi atau alat tidak bekerja yang mana seharusnya dapat bekerja adalah sebesar $11,11 \%$.

d. Penggunaan Efektif (Efektif Utilization)

Penggunaan Efektif (Efektif Utilization) merupakan cara yang paling efektif untuk menyatakan efisiensi kerja dari alat berdasarkan data-data kerja dari alat yang ada dilapangan, dan alat tersebut dapat dugunakan sebesar $88,78 \%$ dari waktu kerja yang ada, atau sebesar $11,22 \%$ dalam keadaan tidak digunakan.

3.5.11 Primary Jaw Crusher

a. Kesediaan Mekanis (Mechanical Availability)

Kesediaan mekanis (Mechanical Availability) pada Primary Jaw Crusher adalah sebesar 95,45\% yang berarti bahwa waktu yang diperlukan untuk memperbaikan karena kerusakan pada alat sebesar 4,55\% dari waktu kerja alat.

b. Kesediaan Fisik (Physical Avaibility)

Kesediaan Fisik (Physical Avaibility) pada Primary Jaw Crusher adalah sebesar 95,94\% yang berarti bahwa waktu yang hilang karena berbagai alasan, baik karena kerusakan alat atau hambatan lainnya yaitu sebesar 4,06\% dari waktu kerja yang di jadwalkan.

c. Kesediaan pemakaian (Use Of Avaibility)

Kesediaan pemakaian (Use Of Avaibility) pada Primary Jaw Crusher adalah sebesar 88,89\% sehingga tingkat penggunakan alat pada saat alat tersebut dapat bekerja cukup tinggi atau alat tidak bekerja yang mana seharusnya dapat bekerja adalah sebesar $11,11 \%$.

d. Penggunaan Efektif (Efektif Utilization)

Penggunaan Efektif (Efektif Utilization) merupakan cara yang paling efektif untuk menyatakan efisiensi kerja dari alat berdasarkan data-data kerja dari alat yang ada dilapangan, dan alat tersebut dapat digunakan sebesar $85,28 \%$ dari waktu kerja yang ada, atau sebesar $14,72 \%$ dalam keadaan tidak digunakan.

3.5.12 Secondary Jaw Crusher

a. Kesediaan Mekanis (Mechanical Availability)

Kesediaan mekanis (Mechanical Availability) pada Secondary Jaw Crusher adalah sebesar 100\% ini berarti tidak ada hambatan yang terjadi pada kesediaan mekanis Secondary Jaw Crusher 


\section{Journal Of Metallurgical Engineering And Processing Technology,}

Vol. 2, No. 2, February 2022, pp. 80-88

P-ISSN: 2723-6854, E-ISSN: 2798-1037

b. Kesediaan Fisik (Physical Avaibility)

Kesediaan Fisik (Physical Avaibility) pada Secondary Jaw Crusher adalah sebesar 100\% ini berarti tidak ada hambatan pada kesediaan fisik Secondary Jaw Crusher.

c. Kesediaan pemakaian (Use Of Avaibility)

Kesediaan pemakaian (Use Of Avaibility) pada Secondary Jaw Crusher adalah sebesar $88,88 \%$ sehingga tingkat penggunakan alat pada saat alat tersebut dapat bekerja cukup tinggi atau alat tidak bekerja yang mana seharusnya dapat bekerja adalah sebesar $11,12 \%$.

d. Penggunaan Efektif (Efektif Utilization)

Penggunaan Efektif (Efektif Utilization) merupakan cara yang paling efektif untuk menyatakan efisiensi kerja dari alat berdasarkan data-data kerja dari alat yang ada dilapangan, dan alat tersebut dapat digunakan sebesar $88,88 \%$ dari waktu kerja yang ada, atau sebesar $11,12 \%$ dalam keadaan tidak digunakan.

\subsubsection{Tertiary Vertical Shaft Crusher}

a.Kesediaan Mekanis (Mechanical Availability)

Kesediaan mekanis (Mechanical Availability) pada Tertiary Vertical Shaft Crusher adalah sebesar $99,01 \%$ yang berarti bahwa waktu yang diperlukan untuk memperbaikan karena kerusakan pada alat sebesar 0,99\% dari waktu kerja alat.

b. Kesediaan Fisik (Physical Avaibility)

Kesediaan Fisik (Physical Avaibility) pada Tertiary Vertical Shaft Crusher adalah sebesar $99,12 \%$ yang berarti bahwa waktu yang hilang karena berbagai alasan, baik karena kerusakan alat atau hambatan lainnya yaitu sebesar $0,88 \%$ dari waktu kerja yang di jadwalkan.

c. Kesediaan pemakaian (Use Of Avaibility)

Kesediaan pemakaian (Use Of Avaibility) pada Tertiary Vertical Shaft Crusher adalah sebesar 88,88\% sehingga tingkat penggunakan alat pada saat alat tersebut dapat bekerja cukup tinggi atau alat tidak bekerja yang mana seharusnya dapat bekerja adalah sebesar $12,12 \%$.

\section{d. Penggunaan Efektif (Efektif Utilization)}

Penggunaan Efektif (Efektif Utilization) merupakan cara yang paling efektif untuk menyatakan efisiensi kerja dari alat berdasarkan data-data kerja dari alat yang ada dilapangan, dan alat tersebut dapat digunakan sebesar $88,11 \%$ dari waktu kerja yang ada, atau sebesar 11,89\% dalam keadaan tidak digunakan.

\subsubsection{Screen}

Kesediaan Mekanis (Mechanical Availability)

Kesediaan Mekanis (Mechanical Availability) pada Screen adalah sebesar 100\% ini berarti tidak ada hambatan pada kesediaan mekanis screenKesediaan Fisik (Physical Avaibility)

Kesediaan Fisik (Physical Avaibility) oada Screen adalah sebesar $100 \%$ ini berarti tidak ada hambatan pada kesediaan fisik screen.

Kesediaan Pemakaian (Use Of Avaibility)

Kesediaan Pemakaian (Use Of Avaibility) pada
Screen adalah sebesar 88,88\% sehingga tingkat penggunaan alat pada saat alat tersebut dapat bekerja cukup tinggi atau alat tidak bekerja yang mana seharusnya dapat bekerja adalah sebesar 11,12\% Penggunaan Efektif (Efektif Utilization)

Penggunaan Efektif (Efektif Utilization) merupakan cara yang paling efektif untuk menyatakan efisiensi kerja dari alat berdasarkan data-data kerja dari alat yang ada dilapangan, dan alat tersebut dapat digunakan sebesar $88,88 \%$ dari waktu kerja yang ada, atau sebesar $11,12 \%$ dalam keadaan tidak digunakan.

3.5.15 Belt Conveyor

a. Kesediaan Mekanis(Mechanical Availability)

Kesediaan mekanis (Mechanical Avaibility) pada Belt Conveyor adalah sebesar 100\% ini berarti tidak ada hambatan pada kesediaan mekanis Belt Conveyor.

b. Kesediaan Fisik (Physical Avaibility)

Kesediaan Fisik (Physical Avaibility) pada Belt Conveyor adalah sebesar $100 \%$ ini berarti tidak ada hambatan pada kesediaan fisik Belt Conveyor.

c. Kesediaan Pemakaian (Use Of Avaibility)

Kesediaan pemakaian (Use Of Avaibility) pada Belt Conveyor adalah sebesar $88,88 \%$ sehingga tingkat penggunaan alat pada saat alat tersebut dapat bekerja cukup tinggi atau alat tidak bekerja yang mana seharusnya dapat bekerja adalah sebesar $11.12 \%$

\section{d. Penggunaan Efektif (Efektif Utilization)}

Penggunaan Efektif (Efektif Utilization) merupakan cara yang paling efektif untuk menyatakan efisiensi kerja dari alat berdasarkan data-data kerja dari alat yang ada dilapangan, dan alat tersebut dapat digunakan sebesar $88,88 \%$ dari waktu kerja yang ada, atau sebesar $11,12 \%$ dalam keadaan tidak digunakan.

3.5.16 Hopper

a. Kesediaan Mekanis (Mechanical Availability)

Kesediaan mekanis (Mechanical Availability) pada Hopper adalah sebesar $99,07 \%$ yang berarti bahwa waktu yang diperlukan untuk memperbaikan karena kerusakan pada alat sebesar $0,93 \%$ dari waktu kerja alat.

b. Kesediaan Fisik (Physical Avaibility)

Kesediaan Fisik (Physical Avaibility) pada Hopper adalah sebesar $99,18 \%$ yang berarti bahwa waktu yang hilang karena berbagai alasan, baik karena kerusakan alat atau hambatan lainnya yaitu sebesar $0,82 \%$ dari waktu kerja yang di jadwalkan.

c. Kesediaan pemakaian (Use Of Avaibility)

Kesediaan pemakaian (Use Of Avaibility) pada Hopper adalah sebesar $88,89 \%$ sehingga tingkat penggunakan alat pada saat alat tersebut dapat bekerja cukup tinggi atau alat tidak bekerja yang mana seharusnya dapat bekerja adalah sebesar $11,11 \%$.

\section{d. Penggunaan Efektif (Efektif Utilization)}

Penggunaan Efektif (Efektif Utilization) merupakan cara yang paling efektif untuk menyatakan efisiensi kerja dari alat berdasarkan 


\section{Journal Of Metallurgical Engineering And Processing Technology,}

Vol. 2, No. 2, February 2022, pp. 80-88

P-ISSN: 2723-6854, E-ISSN: 2798-1037

data-data kerja dari alat yang ada dilapangan, dan alat tersebut dapat digunakan sebesar $88,17 \%$ dari waktu kerja yang ada, atau sebesar $11,83 \%$ dalam keadaan tidak digunakan.

\subsection{Upaya Peningkatan Produksi}

Tidak tercapainya target produksi di PT. Gunung Puncak Salam dengan target produksi yang di tetapkan oleh perusahaan sebesar 800 ton/hari atau 100 ton/jam. Maka harus dilakukan upaya - upaya untuk mencapai target produksi antara lain yaitu upaya mengurangi waktu hambatan karena faktor manusia maupun karena faktor alat, untuk mencapai efektifitas kerja yang optimal, upaya penambahan umpan perlu dillakukan karena umpan yang masuk kedalam Hopper terlalu sedikit sehingga target produksi tidak tercapai maka dari itu perlu penambahan umpan sehingga bisa tercapai target produksi yang diinginkan.

3.6.1 Pembahasan perbaikan waktu hambatan faktor manusia dan faktor alat

Waktu hambatan yang disebabkan oleh faktor manusia dan faktor alat sangat berpengaruh terhadap proses produksi untuk mencapai target produksi yang ditetapkan oleh perusahaan, maka penyusun melakukan perbaikan pada waktu hambatan tersebut untuk mengoptimalkan waktu kerja efektif, supaya target yang diharapkan bisa tercapai, dan perbaikan yang dilakukan adalah mengurangi waktu hambatan yang terjadi pada proses produksi yang disebabkan oleh faktor manusia dan faktor alat, sebelum melaukan perbaikan waktu produksi efektif perhari adalah 6,95 jam/hari, maka penyusun melakukan perbaikan waktu produksi efektif perhari menjadi 8,41 jam/hari,diharapkan agar bisa mencapai target produksi,setelah melakukan perbaikan pada waktu hambatan yang disebabkan oleh kedua faktor tersebut ternyata target produksi yang ditentukan belum juga tercapai.

3.6.2 Pembahasan perbaikan umpan masuk

Perbaikan umpan masuk dilakukan untuk meningkatkan produksi. Pada saat ini produksi sebelum melakukan perbaikan pada umpan masuk adalah 618,1 ton/hari,dari hasil tersebut menunjukan target produksi yang ditetapkan oleh perusahaan belum tercapai maka diperlukan perbaikan terhadap umpan masuk dan penyusun melakukan perbaikan umpan masuk dengan menambahkan ritase dump truck butujuan agar target produksi bisa tercapai dan setelah melakukan perbaikan produksi meningkat menjadi 625,5 tom/hari, dan produksi belum juga tercapai target yang ditetapkan oleh perusahaan.

3.6.3 Pembahasan perbaikan menggunakan penggabungan antara perbaikan waktu hambatan dan perbaikan umpan masuk

Perbaikan penggabungan antara waktu hambatan dan umpan masuk perlu dilakukan dikarenakan jika hanya melakukan perbaikan pada salah satu faktor saja maka target produksi hanya meningkat beberapa persen saja dari yang sebelumnya. Maka dari itu penyusun melakukan perbaikan menggunakan perbaikan penggabungan antara dua faktor tersebut dan hasilnya bisa tercapai target produksi yang di inginkan oleh perusahaan bahkan melebihi target produksi dari perusahaan. Produksi sebelum melakukan perbaikan penggabungan adalah sebesar 618,1 ton/hari, dan setelah melakukan perbaikan penggabungan meningkat menjadi 841 ton/hari.

\section{KESIMPULAN}

Berdasarkan hasil pembahasan bab sebelumnya dapat disimpulkan bahwa:

1. Produk Unit Crushing Plant pada saat ini sebesar 618,1 ton/hari atau 70 ton/jam dengan waktu kerja efektif sebesar 6,95 jam/hari, sedangkan target produksi sebesar 800 ton/hari atau 100 ton/jam.

2. Faktor - fator yang berpengaruh terhadap produksi ada dua faktor yaitu faktor manusia dan faktor alat.Total waktu hambatan pada Unit Crushing Plant sebesar 112,83 menit/hari atau $1,88 \mathrm{jam} /$ hari terdiri dari hambatan oleh faktor manusia 79,80 menit/hari atau $1,33 \mathrm{jam} /$ hari dan hambatan oleh faktor alat 33,03 menit/hari atau 0,55 jam/hari,dengan efisiensi waktu kerja sebesar $77,76 \%$.

3. Produksi dapat di tingkatkan dengan melakukan perbaikan terhadap waktu kerja efektif manusia, alat dan perbaikan umpan masuk perbaikan ketiga faktor ini dapat meningkatkan produksi menjadi 841 ton/hari.

\section{DAFTAR PUSTAKA}

1. Agus Kuntoro. 2008. Crusher Operation dan Sistem Pemeliharaan

2. Gaudin, AM, 1939. Principles of Mineral Dressing, Mc. Graw Hill Book Company Inc, New York.

3. Hartman, HL, 1987. Introductory Mining Engineering, A Willey-Interscience Publication, John Willey and sons, New York

4. Kurimoto. 2004. Crushing \& Screening, Reference, Kurimoto, Ltd"

5. Sukamto. 2001. "Pengolahan Bahan Galian". Jurusan Teknik Pertambangan, Fakultas Teknologi Mineral, Universitas Pembangunan Nasional "Veteran", Yogyakarta.

6. Suwandhi. 2004. "Peremukan Mekanis Kominusi”. Diktat Perencanaan Tambang Terbuka. Universitas Negeri Islam Bandung.

7. Wills, B. A dan Tiim Napier-Munn, 2006, Mineral Processing Technology 7th edition, Elsevier Science and Technology Books, Queensland

8. Yardley, E. D dan L. R. Stace, 2008, Belt Conveying of Minerals, Woodhead Publishing Limited, England 